\title{
Plasma Copper and Antioxidant Status in Wilson's Disease
}

\author{
HIROMI OGIHARA, TOHRU OGIHARA, MASAYUKI MIKI, HIROSHI YASUDA, AND \\ MAKOTO MINO
}

Department of Pediatrics, Osaka Medical College, 2-7 Daigaku-machi, Takatsuki, Osaka 569, Japan

\section{ABSTRACT}

It has been demonstrated that the level of serum copper unbound to ceruloplasmin (loosely bound copper) is increased in Wilson's disease, although the total serum copper concentration is usually low, reflecting a low ceruloplasmin level. To assess the contribution of free radical reactions catalyzed by nonceruloplasmin copper to the development of complications in this disease, we investigated copper and antioxidant status in four untreated patients who had hepatic dysfunction with or without hemolytic anemia and made a comparison with five patients controlled on penicillamine therapy and 19 age-matched healthy children. We found that loosely bound copper in plasma measured by the phenanthroline assay was detectable in three of four untreated patients with Wilson's disease, but was not detectable in the patients during therapy or in the healthy controls. Among the various antioxidants, the ascorbate and urate levels were markedly reduced before treatment (mean $\pm \mathrm{SD}, 23 \pm 16 \mu \mathrm{M}$ for ascorbate and $90 \pm 59 \mu \mathrm{M}$ for urate) compared with the values in the patients during treatment with penicillamine $(67 \pm 19$ and $302 \pm 78 \mu \mathrm{M}, p<0.05)$ and in control children $(60 \pm 8$ and 254 $\pm 48 \mu \mathrm{M}, p<0.05$ ). We also demonstrated that the plasma concentration of allantoin, an oxidation product of uric acid and a possible marker of radical generation in vivo, was markedly elevated in the untreated patients $(11.0 \pm 1.8$ versus $4.3 \pm 0.5$ $\mu \mathrm{M}$ in patients on therapy and $6.5 \pm 0.8 \mu \mathrm{M}$ in controls, $p<$
$0.05)$. The low plasma urate level together with the elevation of allantoin were thought to be responsible for the degradation of uric acid as a sacrificial antioxidant. In contrast, the plasma levels of $\alpha$-tocopherol and thiobarbituric acid reactive substances did not differ in these three groups. The value of the total radicaltrapping antioxidant parameter was reduced in the patients before the initiation of therapy $(372 \pm 146$ versus $942 \pm 79 \mu \mathrm{M}$ in patients on therapy and $856 \pm 104 \mu \mathrm{M}$ in controls, $p<0.05$ ), and this was mainly attributed to the depletion of ascorbic acid and uric acid. These findings suggest that the elevation of loosely bound copper leads to transition metal catalyzed free radical reactions in the aqueous phase of plasma, which may play a role in the clinical complications of Wilson's disease. (Pediatr Res 37: 219-226, 1995)

\section{Abbreviations}

TBARS, thiobarbituric acid reactive substance

AAPH, 2,2'-azobis (2-amidinopropane) dihydrochloride

TRAP, total radical-trapping antioxidant parameter

TRAPmeas, experimentally measured TRAP

TRAPcalc, theoretically calculated TRAP

TRAPdiff, difference between TRAPmeas and TRAPcalc GPT, glutamic pyruvic transaminase
Wilson's disease is an inherited disorder of copper metabolism characterized by the defective biliary excretion of copper and impairment of its incorporation into ceruloplasmin. These defects result in the accumulation of copper in the liver with progressive hepatic damage and subsequent redistribution to various extrahepatic tissues including the brain, kidneys, and cornea $(1,2)$. Although the total serum copper concentration is not always high in Wilson's disease due to a low ceruloplasmin level (1), the nonceruloplasmin copper level is still expected to be high $(3,4)$. In particular, tissue copper may be released into

Received January 9, 1994; accepted July 15, 1994.

Correspondence: Tohru Ogihara, M.D., Ph.D., Department of Pediatrics, Osaka Medical College, 2-7 Daigaku-machi, Takatsuki, Osaka 569, Japan.

Supported by a Grant-in-Aid (03670513) for Scientific Research from the Ministry of Education, Science, and Culture and a grant from the Uehara Foundation, Japan. Financial assistance was also provided by Eisai Co. Ltd., Tokyo. the circulation in massive amounts during episodes of acute liver insufficiency, and the nonceruloplasmin copper level is thought to be comparable to that seen in acute copper poisoning (1). However, elevation of the nonceruloplasmin copper level in Wilson's disease has generally been assumed on the basis of calculation of the difference between the saturation copper binding to ceruloplasmin (six atoms per molecule) and the total serum copper concentration, and direct measurement of free plasma copper levels has only been performed in a few studies (5). In our study, we attempted to measure loosely bound copper levels in plasma directly using a sensitive phenanthroline assay (6) to confirm that those levels were actually increased in untreated patients.

Free radical production by reactions involving plasma nonceruloplasmin copper has been proposed as the cause of acute hemolysis and multiple organ insufficiency in association with 
severe liver damage in Wilson's disease (7), but this has not been proved. If copper ions released from the liver into the blood catalyze the generation of free radicals, the consumption of radical-trapping plasma antioxidants might be a possible initial event. To assess the antioxidant status in Wilson's disease, we measured ascorbic acid, sulfhydryl groups, and uric acid as plasma aqueous antioxidants and $\alpha$-tocopherol as an antioxidant in the plasma lipid phase. Together with ascorbic acid, uric acid is thought to be one of the major antioxidants in plasma (8), and it acts as a sacrificial radical scavenger with the resultant generation of oxidation products such as allantoin (9). Therefore, the measurement of allantoin might be a proposal "marker" of free radical generation in vivo (10). With this in mind, we additionally measured the plasma allantoin concentration in Wilsonian patients and compared it with that in age-matched healthy children.

The total antioxidant capacity of plasma is dependent on the synergism between various antioxidants (11) in addition to the capacity of each single antioxidant acting alone. Although a test has been developed to measure the TRAP of plasma (12), these potentially important interactions have only been explored in a few clinical studies (13-15). In this study, we also measured the TRAP value to evaluate the total plasma antioxidant capacity in Wilsonian patients. In addition, we investigated the change with time in all the parameters mentioned above in two patients with Wilson's disease before and during penicillamine therapy.

\section{METHODS}

\section{Subjects}

We investigated four patients with Wilson's disease before starting penicillamine therapy (two boys and two girls; mean age $10.5 \mathrm{y}$ ), five Wilsonian patients during therapy (four boys and one girl; mean age $12.5 \mathrm{y}$, including two of the patients examined before therapy), and 19 age-matched controls (seven boys and 12 girls; mean age $12.3 \mathrm{y}$ ) who attended our outpatient clinics either for health checks or with various minor symptoms such as fever, cough, headache, and motion sickness. The study protocol was approved by the ethical committee of our college hospital and the studies were performed after informed consent was obtained. The diagnosis of Wilson's disease $(16,17)$ was confirmed in all patients on the basis of clinical features and their copper metabolism, i.e. a low serum ceruloplasmin level $(<1.5 \mu \mathrm{M})$, a low serum copper concentration $(<12 \mu \mathrm{M})$, a high urinary copper excretion, both basal $(>1.5 \mu \mathrm{M} / \mathrm{d})$ and after oral D-penicillamine $(>25 \mu \mathrm{M} / \mathrm{d})$, and/ or elevated concentration of liver copper $(>250 \mu \mathrm{g} / \mathrm{g}$ dry weight). The laboratory data of the patients are summarized in Table 1, and details of clinical courses are given below.

Patient 1. A previously well 10-y-old girl occasionally passed tarry stool for about 6 mo. She developed malaise and nausea, and she vomited "coffee grounds" liquid $2 \mathrm{wk}$ before admission. On admission to our hospital, she was found to have hepatomegaly, with the liver edge palpable $3 \mathrm{~cm}$ below the costal margin, and abdominal distension due to ascites. Laboratory tests showed anemia, but hemolysis was not obvious because of a normal haptoglobin level $(220 \mathrm{mg} / \mathrm{dL})$ and no

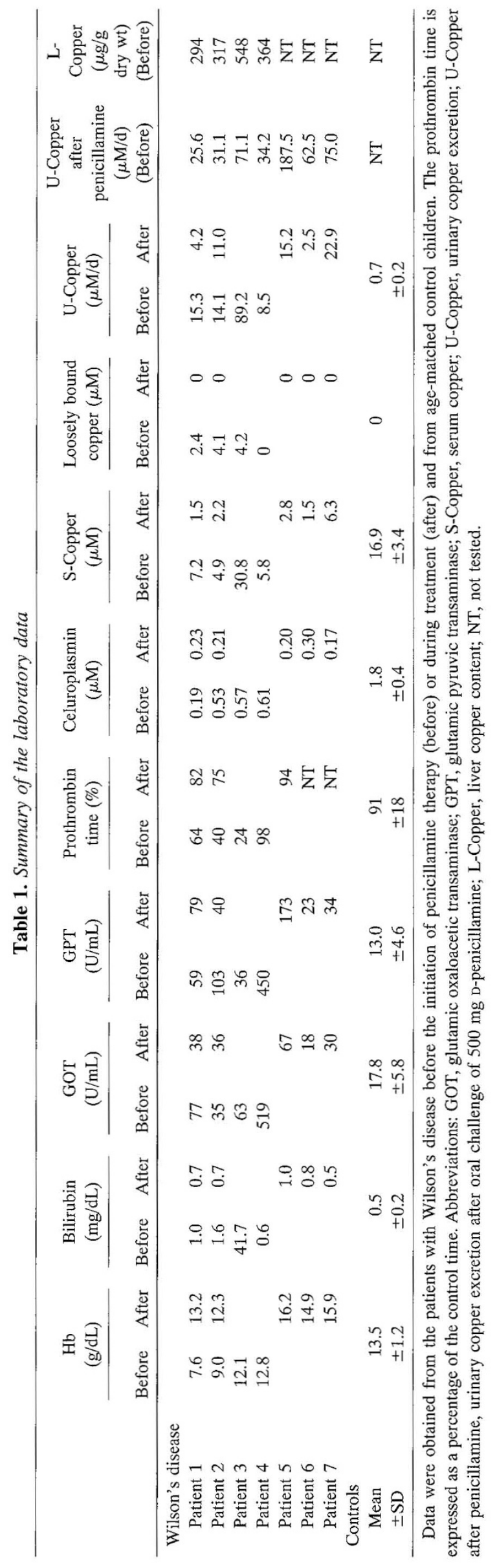


hyperbilirubinemia. Coagulation was impaired, with a prolonged prothrombin time and reduction of the thrombotest to $22.5 \%$ of the normal level. Liver biopsy showed cirrhotic change with patchy necrosis, many regenerating nodules, and excessive deposition of copper with an elevated liver copper concentration. Treatment was initiated with penicillamine, and the dose was $1000 \mathrm{mg} / \mathrm{d}$ at $30 \mathrm{mo}$ after admission when the plasma sample during therapy was obtained. Zinc sulfate $(600$ $\mathrm{mg} / \mathrm{d}$ ) was added from 6 mo after the start of therapy due to prolonged mild elevation of the transaminases. She recovered fully within an 8-mo period.

Patient 2. A previously healthy 12 -y-old boy was admitted to our hospital because of painful pretibial edema, abdominal distention, and malaise lasting for about $1 \mathrm{wk}$. Physical examination revealed ascites and jaundice without hepatosplenomegly. Hemolysis was evidenced by mild anemia with a reticulocyte count of $11.2 \%$, hyperbilirubinemia, negative direct and indirect Coombs' tests, and a low haptoglobin level $(<30 \mathrm{mg} / \mathrm{dL})$. A clotting abnormality was demonstrated with a prolonged prothrombin time, reduction of the hepaplastin test to $25 \%$ of normal, and thrombotest reduction to $32 \%$ of normal. Liver biopsy showed fatty change, mild enlargement of the portal tracts with fibrosis and infiltration, and excessive copper deposition with a raised hepatic copper level. He was started on penicillamine, and the dose was increased to 800 $\mathrm{mg} / \mathrm{d}$ at the time when the plasma sample during therapy was taken. A gradual improvement of both clinical and biochemical parameters was observed.

Patient 3. A 12-y-old girl had developed elevated transaminase levels 2 y previously and was followed up thereafter. When she was admitted to the Wakayama Medical School Hospital for further workup, slit lamp examination of the eyes demonstrated corneal Kayser-Fleischer rings and liver biopsy revealed early cirrhosis with marked elevation of the hepatic copper content. She was diagnosed as having Wilson's disease and was immediately started on penicillamine therapy. Three mo later, while the penicillamine dose was being gradually increased with monitoring of urinary copper excretion, she experienced fatigability accompanied by jaundice and was readmitted. Her general condition deteriorated rapidly leading to coma. Laboratory tests provided evidence of Coombs'negative hemolytic anemia as demonstrated by indirect hyperbilirubinemia and a low haptoglobin level $(<30 \mathrm{mg} / \mathrm{dL})$ as well as severe coagulation abnormalities (a markedly prolonged prothrombin time and a hepaplastin test that was only $20 \%$ of normal). She underwent frequent exchange transfusion or total plasma exchange, and triethylene tetramine dihydrochloride and dimercaprol were given together with penicillamine. Despite intensive cares, she died of combined hepatic and renal failure at 2 mo after readmission.

Patient 4. An 8-y-old boy attended our hospital with fever and cough due to a viral infection. Elevation of the transaminases was unexpectedly detected and he was admitted for further evaluation of liver function. The liver edge was palpable $2 \mathrm{~cm}$ below the right costal margin. Studies of his copper metabolism suggested Wilson's disease and the diagnosis was confirmed by elevation of the hepatic copper content with fatty change and intralobular spotty necrosis. Immediately after the definitive diagnosis, treatment with penicillamine $(300 \mathrm{mg} / \mathrm{d})$ was instituted. However, penicillamine was discontinued at a dose of $400 \mathrm{mg} / \mathrm{d}$ due to fever and was changed to Trientine at 2 mo after admission.

Patient 5. A 10-y-old-boy was admitted with a 3-d history of frequent vomiting and jaundice. Before this illness, a preliminary diagnosis of chronic hepatitis with elevation of the transaminases had been made and follow-up had continued. His parents were consanguineous. On examination, he was icteric, the liver edge was $4 \mathrm{~cm}$ below the costal margin, and corneal Kayser-Fleischer rings were found. Within $1 \mathrm{wk}$, he developed signs of fulminant hepatitis leading to coma. Laboratory tests showed marked elevation of the transaminases (glutamic oxaloacetic transaminase, 3720 IU; GPT, 1086 IU), hemolysis $(\mathrm{Hb}, 5.2 \mathrm{~g} / \mathrm{dL}$; reticulocyte count, 32.8\%; indirect bilirubin, $19 \mathrm{mg} / \mathrm{dL}$; and haptoglobin, $<30 \mathrm{mg} / \mathrm{dL}$ ), and severe clotting abnormalities (prothrombin time, 21\%; thrombotest, $30 \%$ of normal). Abnormalities of copper metabolism were also noted that were characteristic of Wilson's disease. The liver biopsy showed precirrhotic liver with irregular regenerating nodules, and copper staining was positive. Frequent exchange transfusion with penicillamine treatment dramatically improved his clinical status. Within $3 \mathrm{wk}$, his symptoms almost disappeared, and the transaminase levels improved after 2 mo. At the age of 14 , a plasma sample was taken for this study during treatment with penicillamine at $1200 \mathrm{mg} / \mathrm{d}$.

Patient 6. An 8-y-old-boy, whose sister and first cousin had Wilson's disease, developed fatigue for 2 mo. Anorexia and nausea ensued 1 mo later and he became jaundiced 2 wk before admission. Physical examination revealed ascites and hepatomegaly (liver edge $2 \mathrm{~cm}$ below the costal margin). Laboratory tests showed abnormal liver function with a glutamic oxaloacetic transaminase of $51 \mathrm{IU}$, a GPT of $63 \mathrm{IU}$, and a direct bilirubin of $18 \mathrm{mg} / \mathrm{dL}$. A diagnosis of Wilson's disease was made on the basis of abnormal copper metabolism, the presence of Kayser-Fleischer rings, and a positive family history. He began treatment with penicillamine, and the jaundice disappeared within $3 \mathrm{wk}$. The plasma sample was taken at the age of 12 during treatment with penicillamine at a dose of 600 $\mathrm{mg} / \mathrm{d}$.

Patient 7. A 9-y-old boy in previously good health developed nausea and vomiting. He was found to have raised transaminase levels by his family doctor and was referred to our hospital. The liver edge was $3 \mathrm{~cm}$ below the costal margin, but no jaundice was noted. Laboratory data were not striking, except for a GPT level of 53 IU. Slit lamp examination revealed Kayser-Fleischer rings, and data on his copper metabolism were compatible with Wilson's disease. Therapy with penicillamine was instituted $10 \mathrm{~d}$ after admission. The plasma sample was obtained at the age of 12 during treatment with penicillamine at $1000 \mathrm{mg} / \mathrm{d}$.

All of these patients had the hepatic form of Wilson's disease: patients 3 and 5 had the fulminant hepatitis type and the others had the acute hepatitis type. Hemolysis was present in patients 2 and 3. Patient 5 was also in hemolytic crisis before the initiation of therapy. None of the patients had any neurologic symptoms. Heparinized blood samples were immediately centrifuged $(1000 \times g, 10 \mathrm{~min})$, and the plasma was stored 
under nitrogen gas at $-80^{\circ} \mathrm{C}$ until analysis within 4 wk. Preliminary studies confirmed that the TRAP value, the levels of various antioxidants, and the phenanthroline-detectable copper level did not change within 6 mo after plasma samples were taken (data not shown).

\section{Determination of Plasma Antioxidants}

The plasma $\alpha$-tocopherol level was measured by a modification of the method of Ishibashi et al. (18), using HPLC with electrochemical detection as described in our previous paper (19). The instruments used were as follows: an IRICA $\Sigma-871$ HPLC (Irica Instruments Inc., Kyoto, Japan); an IRICA RP18T (octadecylsilane) $4 \times 250 \mathrm{~mm}$ column; methanol/water/ $\mathrm{NaClO}_{4}$ eluent at a ratio of $1000 / 2 / 7$ ( $\mathrm{vol} / \mathrm{vol} / \mathrm{wt}$ ) and a flow rate of $1.0 \mathrm{~mL} / \mathrm{min}$; and an IRICA Amperometric $\Sigma-875$ detector with an applied voltage of $700 \mathrm{mV}$.

Determination of plasma ascorbate and urate levels was carried out using a slight modification of the method of Iriyama et al. (20). In brief, $0.1 \mathrm{~mL}$ of plasma was mixed with $0.9 \mathrm{~mL}$ of an aqueous solution containing $10 \%$ metaphosphoric acid and $20 \mathrm{mM}$ deferoxamine mesylate, and the mixture was centrifuged at $3000 \times g$ for $10 \mathrm{~min}$ at $4^{\circ} \mathrm{C}$. A $10-\mu \mathrm{L}$ aliquot of the supernatant was injected directly into the same HPLC system equipped with electrochemical detection used for $\alpha$-tocopherol detection except that the eluent was $0.2 \mathrm{M} \mathrm{KH}_{2} \mathrm{PO}_{4}$ $\mathrm{H}_{3} \mathrm{PO}_{4}$ (pH 3.0) containing $50 \mu \mathrm{M}$ EDTA.

The total plasma sulfhydryl concentration was measured by Ellman's method (21).

\section{Determination of Allantoin}

Allantoin analysis was carried out based on a slight modification of the method described by Grootveld and Halliwell (10). Separated plasma was deproteinized with a $1 / 10$ volume of $100 \%$ trichloroacetate, and an $80-\mu \mathrm{L}$ aliquot of the supernatant was injected directly into an IRICA SCX-1010 ionexchange column $(4 \times 250 \mathrm{~mm})$, with a mobile phase of 60 $\mathrm{mM} \mathrm{KH} \mathrm{PO}_{4}$ adjusted to $\mathrm{pH} 3.0$ with $\mathrm{HCl}$ at a flow rate of 1.0 $\mathrm{mL} / \mathrm{min}$. The HPLC system was identical to that used for antioxidant determinations. A fraction covering the retention time range from 2.0 to $6.5 \mathrm{~min}$, where allantoin was known to be eluted, was collected and then evaporated to dryness at $40^{\circ} \mathrm{C}$ under vacuum. The residue was reconstituted in $300 \mu \mathrm{L}$ of $3 \mathrm{M}$ $\mathrm{NaOH}$ and heated in a boiling water bath for $20 \mathrm{~min}$, then treated with $200 \mu \mathrm{L}$ of $5 \mathrm{M} \mathrm{HCl}$ followed by $30 \mu \mathrm{L}$ of a $3 \mathrm{mM}$ solution of 2,4-dinitrophenylhydrazine in $1 \mathrm{M} \mathrm{HCl}$ with heating for $10 \mathrm{~min}$. After the mixture had been allowed to cool, an $80-\mu \mathrm{L}$ aliquot was injected into an octadecylsilane column identical to that used for determining plasma antioxidants. The mobile phase was $70 \%$ (vol/vol) $30 \mathrm{mM}$ sodium citrate $/ 27.7$ $\mathrm{mM}$ sodium acetate buffer ( $\mathrm{pH} 4.75)$ and $30 \%$ (vol/vol) methanol at a flow rate of $1.0 \mathrm{~mL} / \mathrm{min}$. Glyoxylate 2,4dinitrophenylhydrazone was detected as the allantoin derivative at $360 \mathrm{~nm}$ with a Shimadzu SPD-8AV spectrophotometer (Shimadzu Corp., Kyoto, Japan). A linear standard curve in the range from 1 to $100 \mu \mathrm{M}$ was obtained by treating a series of allantoin (nacalai tesque Inc., Kyoto, Japan) dissolved in $10 \%$ trichloroacetate in the same way as the samples. The plasma allantoin concentration was quantified by comparing the peak area of glyoxylate 2,4-dinitrophenylhydrazone with values from the standard curve. The recovery of three different concentrations of added allantoin $(10,25$, and $50 \mu \mathrm{M})$ to plasma averaged $91.6 \%$ in five replicate analyses of each plasma sample. The mean coefficient of variation for analysis of eight replicate plasma samples was $2.2 \%$.

\section{Measurement of TBARS}

The plasma TBARS level was measured according to the method of Yagi (22), and TBARS values were calculated against a known amount of tetraethoxypropane as the standard.

\section{Measurement of Ceruloplasmin}

The serum ceruloplasmin level was measured by nephelometry (23) and expressed in $\mu \mathrm{M}$ by assuming a molecular weight of 132000 .

\section{Measurement of Copper}

The total plasma copper concentration was determined by atomic absorption spectrophotometry (24). The level of loosely bound copper in plasma was measured by the phenanthroline assay (6). 1,10-Phenanthroline is known as a chelating agent that shows a specificity for copper ions, and this assay is based on the fact that a phenanthroline-copper ion complex degrades DNA in the presence of a reducing agent to yield a thiobarbituric acid-reactive chromogen. On the basis of this reaction, a sensitive and specific assay for loosely bound copper in plasma has been established. Loosely bound copper, such as copper ions attached to albumin or amino acids, is available for chelation by phenanthroline, but copper incorporated into ceruloplasmin is not. Inasmuch as penicillamine does not affect the ability of copper ions to react with phenanthroline, penicillamine-copper complexes should also be measurable with this assay (5). The phenanthroline assay was performed exactly as described in the literature (6) using a HITACHI F-3000 fluorescence spectrophotometer (Hitachi Ltd., Tokyo, Japan). The level of loosely bound copper in plasma was estimated from the fluorescence intensity on the basis of a standard curve for copper concentrations ranging from 1 to $10 \mu \mathrm{M}$, which was established using $\mathrm{CuCl}_{2}$.

\section{TRAP Assay}

The TRAP of plasma was measured according to the method of Wayner et al. (12). The oxidation of linoleic acid in the presence of plasma was induced by AAPH at $37^{\circ} \mathrm{C}$ in $20 \mathrm{mM}$ phosphate buffer ( $\mathrm{pH}$ 7.4) containing $1 \mathrm{mM}$ EDTA and was monitored by following the oxygen consumption using an Oxygraph model 5/6 (Gilson Medical Electronics Inc., Middleton, WI). AAPH generates initiating radicals in the aqueous phase by unimolecular thermal decomposition, and the rate of initiation can be easily controlled by adjusting the concentration and temperature $(25,26)$. The oxidation of linoleic acid was initially inhibited by plasma antioxidants to form an induction period and then progressed rapidly. The duration of the induction period was determined to quantify the TRAP 
ANTIOXIDANTS IN WILSON'S DISEASE

Table 2. Plasma antioxidant concentrations and TRAP values

\begin{tabular}{|c|c|c|c|c|c|c|c|c|c|c|c|c|c|c|}
\hline & \multicolumn{2}{|c|}{ Ascorbate } & \multicolumn{2}{|c|}{ Urate } & \multicolumn{2}{|c|}{$\mathrm{SH}$ groups } & \multicolumn{2}{|c|}{$\alpha$-Tocopherol } & \multicolumn{2}{|c|}{$\mathrm{TRAP}_{\text {meas }}$} & \multicolumn{2}{|c|}{$\mathrm{TRAP}_{\text {calc }}$} & \multicolumn{2}{|c|}{$\mathrm{TRAP}_{\text {diff }}$} \\
\hline & Before & After & Before & After & Before & After & Before & After & Before & After & Before & After & Before & After \\
\hline \multicolumn{15}{|c|}{ Wilson's disease } \\
\hline Patient 1 & 22 & 92 & 90 & 318 & 68 & 328 & 10 & 19 & 399 & 1055 & 197 & 716 & 202 & 339 \\
\hline Patient 2 & 43 & 58 & 65 & 276 & 208 & 228 & 16 & 11 & 325 & 836 & 258 & 555 & 67 & 281 \\
\hline Patient 3 & 5 & & 33 & & 62 & & 15 & & 206 & & 102 & & 104 & \\
\hline Patient 4 & 21 & & 172 & & 265 & & 22 & & 556 & & 391 & & 165 & \\
\hline Patient 5 & & 58 & & 274 & & 340 & & 27 & & 937 & & 621 & & 316 \\
\hline Patient 6 & & 46 & & 425 & & 216 & & 15 & & 917 & & 732 & & 185 \\
\hline Patient 7 & & 83 & & 216 & & 284 & & 17 & & 967 & & 550 & & 417 \\
\hline Mean & $23 *$ & 67 & $90^{*}$ & 302 & 151 & 279 & 16 & 18 & $372 *$ & 942 & $237^{*}$ & 635 & $135^{*}$ & 308 \\
\hline$\pm \mathrm{SD}$ & \pm 16 & \pm 19 & \pm 59 & \pm 78 & \pm 102 & \pm 56 & \pm 5 & \pm 6 & \pm 146 & \pm 79 & \pm 121 & \pm 86 & \pm 60 & \pm 85 \\
\hline \multicolumn{15}{|l|}{ Controls } \\
\hline Mean & \multicolumn{2}{|c|}{60} & \multicolumn{2}{|c|}{254} & \multicolumn{2}{|c|}{273} & \multicolumn{2}{|c|}{20} & \multirow{2}{*}{\multicolumn{2}{|c|}{$\begin{array}{r}856 \\
\pm 104\end{array}$}} & \multicolumn{2}{|c|}{558} & \multicolumn{2}{|c|}{297} \\
\hline$\pm \mathrm{SD}$ & \multicolumn{2}{|c|}{ \pm 8} & \multicolumn{2}{|c|}{ \pm 48} & \multicolumn{2}{|c|}{ \pm 84} & \multicolumn{2}{|c|}{ \pm 6} & & & \multicolumn{2}{|c|}{ \pm 59} & \multicolumn{2}{|c|}{ \pm 68} \\
\hline
\end{tabular}

Data were obtained from the patients with Wilson's disease before the initiation penicillamine therapy (before) or during treatment (after) and from age-matched control children. All values are expressed in $\mu \mathrm{M}$. SH groups, sulfhydryl groups. TRAP meas was obtained by the TRAP assay and TRAP calc $_{\text {was }}$ calculated stoichiometrically from the concentrations of plasma antioxidants as described in "Methods." TRAP diff was obtained by the subtraction of TRAP calc from TRAP meas

${ }^{*} p<0.05$ (Mạnn-Whitney) vs patients with therapy and healthy age-matched controls.

value by using the duration produced by a known quantity of a water-soluble analogue of tocopherol, 6-hydroxy-2,5,7,8tetramethylchroman-2-carboxylic acid (Trolox; Hoffman-La Roche, Nutley, NJ) and the stoichiometric factor, $n=2$. Values obtained in this assay were expressed as TRAPmeas in terms of $\mu \mathrm{M}$. TRAP was also calculated stoichiometrically (TRAPcalc) from the concentrations of plasma antioxidants using the experimentally determined stoichiometric factors (n) and the following equation (12): TRAPcalc $(\mu \mathrm{M})=1.7[\mathrm{VC}]$ $+1.3[\mathrm{UA}]+2.0[\mathrm{VE}]+0.33[\mathrm{SH}]$, where $[\mathrm{VC}]$ represents the concentration of ascorbic acid, [UA] is uric acid, [VE] is $\alpha$-tocopherol, and [SH] is total sulfhydryl groups.

\section{Statistical Analysis}

The statistical significance of differences between groups was evaluated with nonparametric Mann-Whitney U test. $p<$ 0.05 was considered to be significant.

\section{RESULTS}

As shown in Table 1, the loosely bound copper level measured by the phenanthroline assay was increased up to a detectable level in patients 1,2 , and 3 . Conversely, the patients well-controlled on penicillamine as well as the age-matched healthy children had no detectable loosely bound copper in plasma. In patients 1 and 2, loosely bound copper also dropped to undetectable levels after the initiation of penicillamine therapy.

Among the four major plasma antioxidants measured in this study (ascorbic acid, uric acid, sulfhydryl groups, and $\alpha$-tocopherol), the reduction of uric acid in untreated patients was the most notable followed by ascorbic acid, both of which reached statistical significance compared with the patients during therapy and the healthy controls (Table 2). In addition, the allantoin concentration was elevated more than 2 -fold and the ratio of allantoin to uric acid was increased about 10 -fold in the patients before the initiation of therapy when compared with the well-controlled patients and the healthy children (Table 3 ).
Table 3. Allantoin concentrations and TBARS values

\begin{tabular}{|c|c|c|c|c|c|c|}
\hline & \multicolumn{2}{|c|}{$\begin{array}{l}\text { Allantoin } \\
(\mu \mathrm{M})\end{array}$} & \multicolumn{2}{|c|}{$\begin{array}{c}\text { Allantoin/urate } \\
(\%)\end{array}$} & \multicolumn{2}{|c|}{$\begin{array}{c}\text { TBARS } \\
(\mu \mathrm{M})\end{array}$} \\
\hline & Before & After & Before & After & Before & After \\
\hline \multicolumn{7}{|c|}{ Wilson's disease } \\
\hline Patient 1 & 11.3 & 4.5 & 12.6 & 1.4 & 2.1 & 2.4 \\
\hline Patient 2 & 10.0 & 4.1 & 15.4 & 1.5 & 2.4 & 2.4 \\
\hline Patient 3 & 9.2 & & 27.9 & & 2.7 & \\
\hline Patient 4 & 13.3 & & 7.7 & & 2.6 & \\
\hline Patient 5 & & 4.8 & & 1.8 & & 2.6 \\
\hline Patient 6 & & 4.7 & & 1.1 & & 2.1 \\
\hline Patient 7 & & 3.5 & & 1.6 & & 2.2 \\
\hline Mean & $11.0^{*}$ & 4.3 & $15.9^{*}$ & 1.5 & 2.5 & 2.3 \\
\hline$\pm \mathrm{SD}$ & \pm 1.8 & \pm 0.5 & \pm 8.6 & \pm 0.3 & \pm 0.3 & \pm 0.2 \\
\hline \multicolumn{7}{|l|}{ Controls } \\
\hline Mean & \multirow{2}{*}{\multicolumn{2}{|c|}{$\begin{array}{r}6.5 \\
\pm 0.8\end{array}$}} & \multirow{2}{*}{\multicolumn{2}{|c|}{$\begin{array}{r}2.3 \\
\pm 0.4\end{array}$}} & \multirow{2}{*}{\multicolumn{2}{|c|}{$\begin{array}{r}2.2 \\
\pm 0.3\end{array}$}} \\
\hline$\pm \mathrm{SD}$ & & & & & & \\
\hline
\end{tabular}

Data were obtained from the patients with Wilson's disease before the initiation of penicillamine therapy (before) or during treatment (after) and from age-matched control children.

${ }^{*} p<0.05$ (Mann-Whitney) $v s$ patients with therapy and healthy agematched controls.

Protein sulfhydryl groups also tended to be lower in the untreated patients, but the difference did not reach statistical significance. In contrast, the $\alpha$-tocopherol concentration and the TBARS level were similar in the untreated patients, the patients receiving therapy, and the controls. The ratio of $\alpha$ tocopherol to total plasma lipids (the sum of total cholesterol, triglycerides, and phospholipids), which is considered to be the most reliable index for the assessment of vitamin E status (27), also showed no significant difference in the three groups (mean $\pm \mathrm{SD}$ : untreated patients, $1.86 \pm 0.83 \mu \mathrm{g} / \mathrm{mg}$; patients receiving therapy, $1.67 \pm 0.36 \mu \mathrm{g} / \mathrm{mg}$; controls, $1.64 \pm 0.12 \mu \mathrm{g} / \mathrm{mg}$ ). The TRAPmeas value in the patients without therapy was significantly lower than in the other two groups, which may have mainly reflected the low plasma levels of uric acid and ascorbic acid. The difference between TRAPmeas and TRAPcalc (i.e. the TRAPdiff level) was also significantly smaller in the untreated patients. 
Figures 1 and 2 represent the clinical course of patients 1 and 2 , respectively, both before and during penicillamine therapy. In both patients, after the start of therapy, the initially reduced urate concentration gradually increased to a level comparable to that in the controls, and a similar trend was observed for the ascorbate level. In contrast, the elevated allantoin level decreased to the normal range and the loosely bound copper level also decreased to become undetectable (data not shown). In association with the increase of antioxidant levels during therapy, a gradual increase of the TRAPmeas value was observed in both patients.

\section{DISCUSSION}

Wilson's disease is known to be caused by genetic defects in the copper transport mechanism (16). One of the essential defects is thought to be impaired biliary excretion of copper (28), which leads to copper accumulation in the liver and subsequent redistribution to the brain, causing liver insufficiency from late childhood onward and neurologic symptoms in mid-adult life $(1,2)$. The incorporation of copper into ceruloplasmin is also impaired in patients with Wilson's disease, so the serum concentrations of ceruloplasmin and copper are usually low (2). In the normal state, about $96 \%$ of serum copper is associated with ceruloplasmin. Therefore, the redistribution of copper to extrahepatic tissues is likely to occur via plasma nonceruloplasmin copper, which means copper ions released into the circulation from damaged hepatocytes that become attached to albumin or amino acids (29).

Gutterridge (6) developed a phenanthroline assay that can measure nonceruloplasmin copper down to a sensitivity of 0.1 $\mu \mathrm{M}$. Using this sensitive method, we have provided evidence that the loosely bound copper level in plasma was elevated in three patients with Wilson's disease before the initiation of penicillamine therapy. Although one of them died of fulminant hepatitis, the other two improved after penicillamine therapy was initiated, and their plasma concentrations of loosely bound

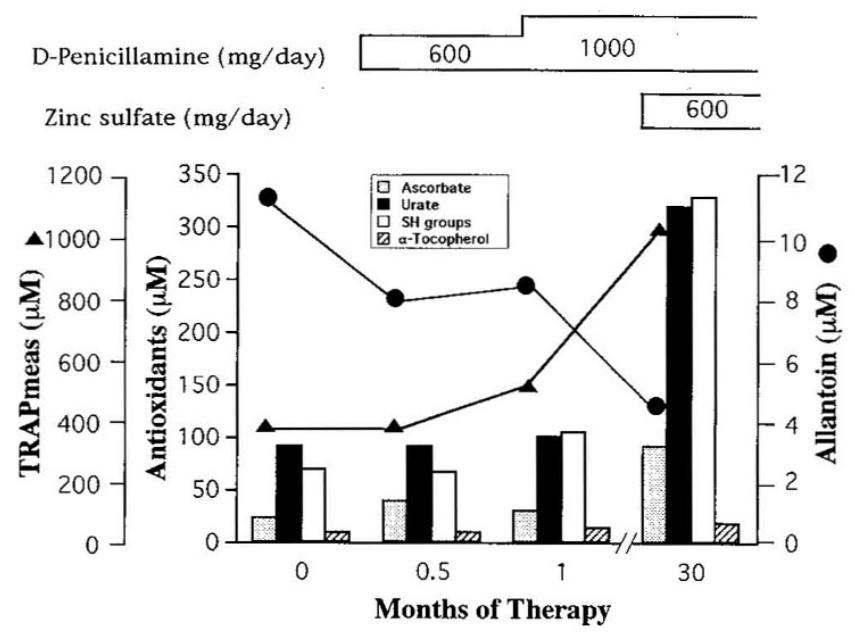

Figure 1. The plasma concentrations of antioxidants and allantoin during therapy in patient 1 . TRAP values are also presented. Bars indicate the level of the various antioxidants shown in the inset, circles show allantoin concentrations, and triangles represent TRAPmeas values. Open bars at the top represent therapy.
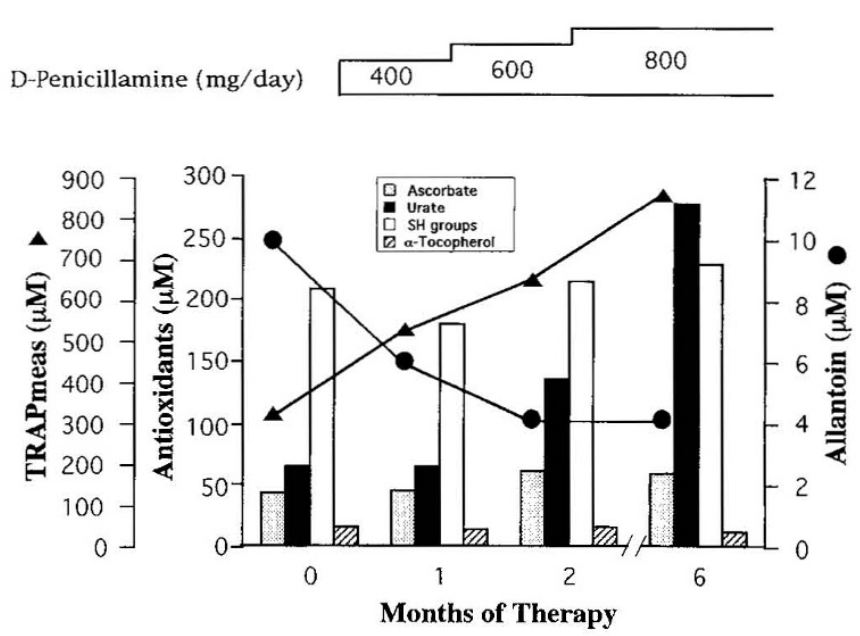

Figure 2. The plasma concentrations of antioxidants and allantoin during therapy in patient 2. TRAP values are also presented. Bars indicate the level of the various antioxidants shown in the inset, circles show allantoin concentrations, and triangles represent TRAPmeas values. Open bars at the top represent therapy.

copper decreased to an undetectable level comparable to that in the patients well controlled on penicillamine. Similarly, Evans et al. (5) have reported that no phenanthroline-detectable copper could be measured in serum freshly prepared from patients with uncomplicated Wilson's disease, whereas it could be measured in serum from a patient with fulminant hepatic failure.

It has been widely recognized that trace amounts of transition metals including copper and iron play a major role in oxidant-induced tissue injury through participation in the generation of active oxygen species and facilitation of lipid peroxidation (30). It is possible that copper ions catalyze the oxidation of ascorbic acid or sulfhydryl groups, in the process reducing molecular oxygen to generate reduced oxygen metabolites such as superoxide and hydrogen peroxide, leading to formation of the highly reactive hydroxyl radical by a mechanism analogous to the Harber-Weiss chemical reaction (31). If loosely bound copper released from the liver catalyzes the generation of free radicals in circulation, the consumption of radical-trapping plasma antioxidants is likely to be an initial event.

In human plasma, ascorbic acid and uric acid are among the most widely cited forms of water-soluble antioxidants and appear to serve as the main defense against oxidizing species in the aqueous phase (32). Uric acid showed the greatest decrease among the various plasma antioxidants in untreated patients with Wilson's disease in our study, and this was accompanied by elevation of the allantoin concentration. During the course of human evolution, the plasma urate level has increased markedly as a consequence of the loss of uricase activity, which further metabolizes uric acid to allantoin (33). Ames et al. (8) have proposed that, with the accompanying loss of ascorbate synthesis, uric acid may have replaced some of the antioxidant functions of ascorbic acid. Uric acid is an end product of purine metabolism in humans, and it may act as a sacrificial antioxidant against hydroxyl radicals, peroxyl radicals, hypochrolous acid, and other hazardous oxidants, with the 
resultant generation of oxidation products such as allantoin (9). It has therefore been proposed that allantoin might be a "marker" of oxidant generation in vivo. Indeed, an increased allantoin concentration has been reported in both plasma and knee-joint synovial fluid obtained from patients with rheumatoid arthritis (10). In our study, we demonstrated a marked elevation of the plasma allantoin concentration and the ratio of allantoin to uric acid in patients with Wilson's disease before the initiation of therapy together with severe urate depletion. Conversely, in the well-controlled patients who had been treated with penicillamine, the levels of uric acid and allantoin were comparable to those in healthy age-matched children. Based on these results, we speculate that free radical reactions catalyzed by loosely bound copper take place in patients with Wilson's disease who fell into pathologic conditions as a consequence of the release of copper from the liver.

Urinary urate clearance in patients with Wilson's disease was previously reported to be increased when compared with that in healthy controls (34). However, we found that the four untreated patients who were tested showed no significant difference in urinary urate clearance (mean $\pm \mathrm{SD}, 12.0 \pm 2.9$ $\mathrm{mL} / \mathrm{min} / \mathrm{m}^{2}$ ) compared with 10 age-matched controls (11.4 \pm $4.0 \mathrm{~mL} / \mathrm{min} / \mathrm{m}^{2}$ ). Fractional excretion of uric acid in untreated patients (mean $\pm \mathrm{SD}, 0.13 \pm 0.04$ ) did not differ from that in controls $(0.13 \pm 0.05)$. Therefore, it is possible that the hypouricemia in untreated patients was derived from urate consumption as an antioxidant rather than from excessive urinary loss.

The plasma ascorbate level was considerably depleted in the untreated patients, and the concentration of sulfhydryl groups was sometimes also decreased. It is widely accepted that ascorbic acid is one of the major aqueous antioxidants in human plasma (35). The decrease of ascorbic acid and sulfhydryl groups in the patients with Wilson's disease may have resulted from their antioxidative degradation, as in the case of uric acid. However, in the presence of transition metals, ascorbic acid and sulfhydryl groups are readily oxidized to generate oxygen radicals and other radical species $(36,37)$. Accordingly, it is also possible that ascorbic acid and sulfhydryl groups acted as prooxidants rather than antioxidants in the untreated patients.

In contrast, no significant consumption of $\alpha$-tocopherol was observed even in the untreated patients. Inasmuch as $\alpha$-tocopherol is the major chain-breaking antioxidant in the lipid phase, in the case where free radicals were produced in the aqueous phase, water-soluble chain-breaking antioxidants would be preferentially consumed $(12,32)$. The fact that the plasma TBARS level, which has been supposed as an index of lipid peroxidation, remained within the normal range also indicates that lipid peroxidation may not contribute much to the oxidative damage that occurs in Wilsonian patients. However, these findings cannot rule out the possibility that copperinduced lipid peroxidation takes place in other tissues, as demonstrated in the livers of copper-overloaded rats (38).

Recent investigations have indicated that plasma antioxidants show synergic interactions in vivo so as to provide greater protection against radical damage than could be achieved by any single antioxidant acting alone (12). For example, it is well established that ascorbic acid can synergistically regenerate $\alpha$-tocopherol (11), and it has also been suggested that uric acid can inhibit ascorbate autooxidation in plasma by formation of stable metal-urate complexes (39). Therefore, a precise understanding of the total plasma antioxidant capacity will require an estimation of the combined effect of various antioxidants in addition to measurement of the individual antioxidants. Wayner et al. (12) developed a test to estimate the TRAP of human plasma and examined the relative importance of each antioxidant. According to the TRAP assay, we found that TRAPmeas values were profoundly reduced in the patients with Wilson's disease before penicillamine therapy when compared with the values in the patients receiving therapy and in the healthy children. This decrease of TRAPmeas values seemed to be attributable mainly to the low plasma levels of uric acid and ascorbic acid. The TRAPcalc values were always lower than the TRAPmeas values, and the most probable explanation for this finding is that TRAPcalc does not take into account the interactions between various antioxidants $(11,12,40)$. Another possible explanation for the remaining gap is that not all the plasma antioxidants were identified and considered. However, although bilirubin, $\beta$-carotene, and ubiquinol have been recognized as important antioxidants, their concentrations are too low to account for a large unidentified antioxidant component (13).

In recent studies, the TRAP assay has given useful information about plasma antioxidant activity in newborn babies (13) and patients with cystic fibrosis (15). However, it has been pointed out that the TRAP assay is not a good model system for assessing the ability to protect against physiologically important reactive oxygen species such as superoxide, hydroxyl radical, and hypochlorous acid, because the antioxidant activity determined by this assay reflects only an ability to scavenge water-soluble peroxyl radicals derived from the decomposition of AAPH. Thus, an ability to scavenge peroxyl radicals gives only a limited part of the plasma capacity to react with physiologic reactive oxidants, a fact that should be kept in mind when interpreting the results obtained by the TRAP assay (32).

Figures 1 and 2 clearly illustrate that, with clinical improvement after the initiation of penicillamine therapy, antioxidant levels were restored to normal in both patients 1 and 2 , and the TRAP values also increased to become comparable to those in control children. Moreover, the plasma allantoin concentration decreased to the control level and there was a converse increase of uric acid. Based on these observations, we propose that the monitoring of plasma urate and allantoin concentrations may provide a useful index for assessment of the clinical status in patients with Wilson's disease. Despite its somewhat limited value, the TRAP assay may also serve as another index for the follow-up of Wilsonian patients.

In conclusion, we demonstrated the possible involvement of oxidative processes contributed to the development of complications in Wilson's disease, but additional studies are needed for the precise mechanism to be clarified.

Acknowledgments. The authors thank Drs. S. Okuda and M. Koike of Wakayama Medical School and are grateful to Drs. T. 
Motoyama, Y. Takenaka, K. Konishi, and A. Yoden for kindly providing blood samples from the patients with Wilson's disease. Thanks are also extended to Y. Tabei and M. Imanishi for their laboratory assistance.

\section{REFERENCES}

1. Danks DM 1989 Disorders of copper transport. In: Scriver CR, Beaudet AL, Sly WS, Valle D (eds) The Metabolic Basis of Inherited Disease. McGraw-Hill, New York, pp 1411-1431

2. Scheinberg IH, Sternlieb I 1984 Wilson's Disease. WB Saunders, Philadelphia, pp 25-37

3. Brewer GJ, Hill GM, Dick RD, Nostrant TT, Sams JS, Wells JJ, Prasad AS 1987 Treatment of Wilson's disease with zinc: III. Prevention of reaccumulation of hepatic copper. J Lab Clin Med 109:526-531

4. Stremmel W, Meyerrose KW, Niederau C, Hefter H, Kreuzpaintner G, Strohmeyer G 1991 Wilson's disease: clinical presentation, treatment, and survival. Ann Intern Med 115:720-726

5. Evans PJ, Bomford A, Halliwell B 1989 Non-caeruloplasmin copper and ferroxidase activity in mammalian serum. Ferroxidase activity and phenanthroline-detectable copper in human serum in Wilson's disease. Free Radic Res Commun 7:55-62

6. Gutteridge JMC 1984 Copper-phenanthroline-induced site-specific oxygen-radical damage to DNA. Detection of loosely bound trace copper in biological fluids. Biochem J 218:983-985

7. Forman SJ, Kumar KS, Redeker AG, Hochstein P 1980 Hemolytic anemia in Wilson's disease: clinical findings and biochemical mechanisms. Am J Hematol 9:269-275

8. Ames BN, Cathcart R, Schwiers E, Hochstein P 1981 Uric acid provides an antioxidant defense in humans against oxidant- and radical-caused aging and cancer: a hypothesis. Proc Natl Acad Sci USA 78:6858-6862

9. Kaur H, Halliwell B 1990 Action of biologically-relevant oxidizing species upon uric acid. Identification of uric acid oxidation products. Chem-Biol Interact 73:235-247

10. Grootveld M, Halliwell B 1987 Measurement of allantoin and uric acid in human body fluids: a potential index of free-radical reactions in vivo? Biochem J 243:803808

11. Niki E 1987 Antioxidants in relation to lipid peroxidation. Chem Phys Lipids 44:227-253

12. Wayner DDM, Burton GW, Ingold KU, Barclay LRC, Locke SJ 1987 The relative contributions of vitamin $\mathrm{E}$, urate, ascorbate and proteins to the total peroxyl radicaltrapping antioxidant activity of human blood plasma. Biochim Biophys Acta 924:408-419

13. Lindeman JHN, Van Zoeren-Grobben D, Schrijver J, Speek AJ, Poorthuis BJHM, Berger HM 1989 The total free radical trapping ability of cord blood plasma in preterm and term babies. Pediatr Res 26:20-24

14. Thurnham DJ, Situnayake RD, Koottathep S, McConkey B, Davies M 1987 Antioxidant status measured by the TRAP assay in rheumatoid arthritis. In: Rice-Evans C (ed) Free Radicals, Oxidant Stress and Drug Action. Richelieu Press, London, pp 169-192

15. Langley SC, Brown RK, Kelly FJ 1993 Reduced free-radical-trapping capacity and altered plasma antioxidant status in cystic fibrosis. Pediatr Res 33:247-250

16. Yarze JC, Martin P, Munoz SJ 1992 Wilson's disease: current status. Am J Med 92:643-654

17. Da Costa CM, Baldwin D, Portmann B, Lolin Y, Mowat AP, Mieli-Vergani G 1992 Value of urinary copper excretion after penicillamine challenge in the diagnosis of Wilson's disease. Hepatology 15:609-615
18. Ishibashi K, Abe K, Ohmae M, Kawabe K, Katsui G 1977 Determination of tocopherols in red blood cells by high-performance liquid chromatography. [in Japanese] Vitamins 51:415-422

19. Tamai H, Manago M, Yokota K, Kitagawa M, Mino M 1988 Determination of $\alpha$-tocopherol in buccal mucosal cells using electrochemical detector. Int J Vitam Nutr Res 58:202-207

20. Iriyama K, Yoshiura M, Iwamoto T, Ozaki Y 1984 Simultaneous determination of uric and ascorbic acids in human serum by reversed-phase high-performance liquid chromatography with electrochemical detection. Anal Biochem 141:238-243

21. Ellman GL 1959 Tissue sulfhydryl groups. Arch Biochem Biophys 82:70-77

22. Yagi K 1976 A simple fluorometric assay for lipoperoxide in blood plasma. Biochem Med 15:212-216

23. Ritchie RF 1967 A simple, direct, and sensitive technique for measurement of specific protein in dilute solution. $\mathrm{J}$ Lab Clin Med 70:512-517

24. Ichida T, Nobuoka M 1969 Determination of serum copper with atomic absorption spectrophotometry. Clin Chim Acta 24:299-303

25. Ogihara T, Kitagawa M, Miki M, Tamai H, Yasuda H, Okamoto R, Mino M 1991 Susceptibility of neonatal lipoproteins to oxidative stress. Pediatr Res 29:39-45

26. Miki M, Tamai H, Mino M, Yamamoto Y, Niki E 1987 Free-radical chain oxidation of rat red blood cells by molecular oxygen and its inhibition by $\alpha$-tocopherol. Arch Biochem Biophys 258:373-380

27. Horwitt MK, Harvey CC, Darm Jr CC, Seary MT 1972 Relationship between tocopherol and serum lipid levels for determination of nutritional adequacy. Ann NY Acad Sci 203:233-236

28. Gibbs K, Walshe JM 1980 Biliary excretion of copper in Wilson's disease. Lancet 2:538-539

29. Cousins RJ 1985 Absorption, transport, and hepatic metabolism of copper and zinc: special reference to metallothionein and ceruloplasmin. Physiol Rev 65:238- 309

30. Halliwell B, Gutteridge JMC 1984 Oxygen toxicity, oxygen radicals, transition metals and disease. Biochem J 219:1-14

31. Hochstein P, Kumar KS, Forman SJ 1980 Lipid peroxidation and the cytotoxicity of copper. Ann NY Acad Sci 355:240-248

32. Halliwell B, Gutteridge JMC 1990 The antioxidants of human extracellular fluids. Arch Biochem Biophys 280:1-8

33. Proctor P 1970 Similar functions of uric acid and ascorbic acid? Nature 228:868

34. Wilson DM, Goldstein NP 1973 Renal urate excretion in patients with Wilson's disease. Kidney Int 4:331-336

35. Frei B, England L, Ames BN 1989 Ascorbate is an outstanding antioxidant in human blood plasma. Proc Natl Acad Sci USA 86:6377-6381

36. Yamamoto $\mathrm{K}$, Takahashi M, Niki E 1987 Role of iron and ascorbic acid in the oxidation of methyl linoleate micelles. Chem Lett 1149-1152

37. Misra H 1974 Generation of superoxide free radical during the autoxidation of thiols. J Biol Chem 249:2151-2155

38. Sokol RJ, Devereaux MW, O'Brien K, Khandwala RA, Loehr JP 1993 Abnormal hepatic mitochondrial respiration and cytochrome $\mathrm{C}$ oxidase activity in rats with long-term copper overload. Gastroenterology 105:178-187

39. Davies KJA, Sevanian A, Muakkassah-Kelly SF, Hochstein P 1986 Uric acid-iron ion complexes. A new aspect of the antioxidant functions of uric acid. Biochem $\mathrm{J}$ 235:747-754

40. Motoyama T, Miki M, Mino M, Takahashi M, Niki E 1989 Synergistic inhibition of oxidation in dispersed phosphatidylcholine liposomes by a combination of vitamin $\mathrm{E}$ and cysteine. Arch Biochem Biophys 270:655-661 